\title{
IRONIA COMO DESTRUIÇÃO DA OBJETIVIDADE EM MACBETH: A TRAGÉDIA SHAKESPEAREANA À LUZ DA TEORIA ESTÉTICA DE HEGEL
}

Irony as destruction of objectivity in Macbeth: the Shakespearean tragedy in the light of Hegel's

aesthetic theory

\author{
Rodrygo Rocha Macedo *
}

Resumo: O presente trabalho propõe demonstrar a aplicabilidade do conceito de Ironia apresentada por Hegel em seus Cursos de Estética dentro de uma produção artística. Para o artigo em questão, selecionou-se a peça Macbeth, escrita pelo dramaturgo inglês William Shakespeare. A partir do objetivo principal do trabalho ora apresentado, mostrar-se-á que os aspectos violentos e fantasmagóricos da aludida peça são manifestações da ironia no autor. Para auxiliar a execução do tema proposto, far-se-á uso de comentários vertidos da pena do teórico da Literatura Harold Bloom. De igual modo, perceber-se-á que a noção do irônico (das Ironische) em Hegel não se restringe apenas a suas exposições sobre estética, mas guarda semelhanças estruturais com elementos importantes do seu método, como é o caso da noção de "consciência infeliz" presente na Fenomenologia do Espírito.

Palavras-chave: Ironia, Hegel, Macbeth.

\begin{abstract}
The present handwork aims to demonstrate the applicability for the concept of Irony showed by Hegel in his Lectures on Aesthetics within the artistic production. The play selected for this article was Macbeth, written by the British playwright William Shakespeare. The main objective of this work will base the idea that violent and ghostly aspects from the selected play are expressions of the author irony. To help the performance of the topic proposed, the comments of the American professor of Literature Harold Bloom. Similarly, it will be noticed that the notion of ironic (das Ironische) in Hegel's work is not restricted to Aesthetic themes, but is very close to the concept of "unhappy consciousness" found in Phenomenology of Mind.

Keywords: Irony, Hegel, Macbeth.
\end{abstract}

* Mestrando do Programa de Pós-Graduação em Filosofia da Universidade Federal do Ceará. E-mail: rodrygorochamacedo@gmail.com

\begin{tabular}{|c|c|l|l|l|l|}
\hline intuitio & $\begin{array}{c}\text { ISSN } \\
1983-4012\end{array}$ & Porto Alegre & Vol.9- $\mathrm{N}^{\mathrm{o} .1}$ & $\begin{array}{l}\text { Julho } \\
2016\end{array}$ & p.98-110 \\
\hline
\end{tabular}




\section{Introdução: Shakespeare e o negativo}

A peça Macbeth aparece, dentre as tragédias de Shakespeare, como a reconhecidamente mais tétrica já saída da pena do bardo. Ainda que não seja incomum encontrar textos do autor pródigos em violência (Tito Andronico, Coriolano ou Ricardo III) e elementos fantásticos (A tempestade, Sonho de uma noite de verão), os citados aspectos nela presente se encontram cerzidos de forma tão precisa a ponto de ser potencializada a tensão da obra encenada, amalgamando as duas características principais de um tratamento "imaginativamente violento" à narrativa. Macbeth e, por consequência, sua esposa, compelidos por predições de bruxas, perpetram atrocidades em prol do cumprimento das profecias destes seres sobrenaturais. A paisagem penumbrosa inferida a partir das falas dos personagens dá, com efeito, mostras de que Shakespeare, antes de tudo, quer promover, pela ambiência fantástica, um plano paralelo de fantasmagoria à base histórica dos eventos trágicos.

O presente artigo propõe aproximar o texto shakespeareano ao conceito de ironia trabalhado pelo filósofo alemão George Wilhelm Friedrich Hegel nos seus Cursos de Estética. De modo a empreender tal correlação, o trabalho ora exposto utilizará, como ferramentas, os escritos do maior expoente em estudos da obra do autor britânico em língua inglesa na contemporaneidade, a saber, o crítico estadunidense Harold Bloom.

\section{A ironia em Hegel}

O fundamento para a compreensão da ironia a que Hegel se refere nos Cursos de Estética é fundada no Eu fichteano e no entendimento de Schlegel sobre a ironia. Ironia é uma pretensa metáfora. De acordo com a definição clássica, entenda-se por irônico quando uma sentença significa outra coisa da qual aparenta significar, ou quando o sentido literal de um objeto difere da sua percepção real ${ }^{1}$.

As três formulações para a ironia repousavam, em Schlegel, nos seguintes aspectos: como paradoxo da autoconsciência, como epideixis (termo grego utilizado para apontar algo entre a demonstração e a indicação, tendo efeito retórico) da infinitude, e como estrutura do amor. A estrutura filosófica principal do romantismo fora enunciada por Schelling na sua descrição de existência como uma eterna tensão entre a ideia (o indeterminado, a essência da liberdade, a expressão do desejo, de uma busca pelo além do aqui e agora) e a realidade (a morte, os limites físicos de um mundo contingentemente determinado). A consciência-de-si vive, nessa tensão, um paradoxo, porque ela precisa ser consciente no

${ }^{1}$ EGGINTON, W. "Cervantes, Irony and making of reality". MLN, Volume 117, Number 5, December 2002 (Comparative Literature Issue), pp. 1040-1068 (Article) Johns Hopkins University Press.

\begin{tabular}{|c|c|l|l|l|l|}
\hline intuitio & $\begin{array}{c}\text { ISSN } \\
1983-4012\end{array}$ & Porto Alegre & Vol.9- $\mathrm{N}^{\circ} .1$ & $\begin{array}{l}\text { Julho } \\
2016\end{array}$ & p.98-110 \\
\hline
\end{tabular}


Ironia como destruição da objetividade em Macbeth: a tragédia shakespeareana à luz da teoria estética de Hegel

mundo, mas também como consciência de que é elemento de um mundo material. Nessa polaridade entre o subjetivo e o objetivo, Schlegel indica que a consciência, na produção artística, se alça do mundo da natureza determinando-se como ser material e apreende a si simultaneamente condicionada e incondicionada, parte espírito, parte mundo. Para Schlegel, a consciência não é expressão de subjetivismo puro e arbitrário, mas expresso pelo paradoxo da criação artística, pois não é criadora nem coisa criada, mas um espaço paradoxal entre as duas coisas ${ }^{2}$.

Para estabelecer a ironia como epideixis da infinitude, deve-se compreender a tensão entre o determinado e o indeterminado. Mas Hegel sentencia que há algo deteriorado em o infinito negar o finito. Os três pontos para compreender o Eu de Fichte, em detrimento do Eu irônico de Schlegel, são ${ }^{3}$ :

1. Estabelecimento de um Eu abstrato e formal como princípio de todo o saber, razão e conhecimento;

2. A adoção da extrema simplicidade do Eu como princípio do conhecimento. De um lado, lhe são negados a particularidade, a determinação e o conteúdo, pois elas sucumbem na liberdade e abstração desse $\mathrm{Eu}$; do outro, o conteúdo só é estabelecido e reconhecido pelo tal Eu já citado. Disso decorre que as coisas que são somente são através do Eu, e devido a isto, têm sua origem nele, o que lhe dá poder para aniquilá-las (pela negatividade desse Eu). Logo, nada externo ao Eu é dotado de valor, apenas o que é produzido pela sua subjetividade. Assim, o em-si-e-para-si (entendido aqui como objetivo e funcionalidade do Eu que transita entre as regiões internas e externas a essa subjetividade) conclui-se como violentamente arbitrário e mera aparência sem efetividade;

3. O Eu deve ser tomado como indivíduo vivo, e sua vida, tal como toda vida que busca a realização de si, consiste em fazer sua individualidade para si e para os outros, manifestando-se e tornandose fenômeno.

Aplicando-se o conceito fichteano de Eu à arte, o artista, substituindo o lugar desse Eu, configura sua vida de modo lúdico (uma característica do ser e fazer arte que são paralelos à vida prosaica, de regras e rotinas, sem o colorido próprio das manifestações do espírito artístico). Ademais, o que o artista

\footnotetext{
${ }^{2}$ Os argumentos de Hegel para refutar o conceito de ironia em Schlegel resultam mais como um atrito entre concepções sobre um mesmo tema do que propriamente um "aperfeiçoamento" das indicações de Schlegel aparentemente utilizadas por Hegel nos Cursos de Estética. EGGINTON, William. "Cervantes, Irony and making of reality". MLN, Volume 117, Number 5, December 2002 (Comparative Literature Issue), pp. 1040-1068 (Article) Johns Hopkins University Press.

${ }^{3}$ HEGEL, G. W. F. Cursos de estética - Volume I. São Paulo: Editora da Universidade de São Paulo, 2001, p. 81-82.
}

\begin{tabular}{|c|c|c|c|c|c|}
\hline intuitio & $\begin{array}{c}\text { ISSN } \\
1983-4012\end{array}$ & Porto Alegre & Vol.9- $\mathrm{N}^{\circ} .1$ & $\begin{array}{l}\text { Julho } \\
2016\end{array}$ & p.98-110 \\
\hline
\end{tabular}


Ironia como destruição da objetividade em Macbeth: a tragédia shakespeareana à luz da teoria estética de Hegel

manifesta está em poder somente dele, servindo apenas de aparência. Nesse sentido, uma vez que o que vale (ou, o que possui conteúdo) é apenas o que está no interior do indivíduo que gera o produto artístico e não aquilo que é apresentado, o efetivo desse produto não é mais levado com seriedade pelo seu produtor. Assim, somente existe o conteúdo da coisa da arte quando o criador artístico o deposita nela. Logo, o que o artista manifesta pode ser tomado pelos outros como algo sério, mas no íntimo do artista a manifestação é um embuste, uma ferramenta de engano ${ }^{4}$.

A ironia então se relaciona a um caráter divino, quando o criador, desvencilhado da sua criação por tornar-se um Outro em relação a ela, pode destruir aquilo que criou. $\mathrm{O}$ artista, nessa etapa final da produção artística, se percebe distinto dos outros homens, considerando-os limitados e rasos. É o momento em que a ironia se encontra completa, pois a obra-de-arte é posta no mundo sempre como algo que quer significar um elemento desse mundo, mas que se antepõe a ele. O próprio objeto de arte é irônico por si. Dessa forma, a ironia pode ser definida como um resultado da concentração do Eu em si mesmo, para quem todos os elos foram quebrados e que somente vive em gozo próprio. O indivíduo-artista quer entrar na objetividade das coisas, identificar nelas o belo e o ético, mas é compelido ao retraimento e à solidão. Sua interioridade é acometida pela nostalgia, uma ausência constatada de vazio que lhe provoca sofrimento 5 .

Para fins de arte, a ironia é um modo de estetização de sujeitos não substanciais, geralmente presente nas realidades históricas em que se apresentam crises de legitimação, mostrando-se, portanto, incapazes de atender a expectativas de validade com aspirações universalizantes. Uma vez que a realidade não corresponde às expectativas da validade, ao sujeito é aberta a possibilidade de mostrar que tal realidade não deve ser tomada a sério, podendo ser invertida ou pervertida. Nesse sentido, a presença do negativo é constante na ironia ${ }^{6}$. É como se a transcendência, condição para que o sujeito se projete no mundo (o para-si), fosse direcionada à realidade, mas retornasse ao sujeito, que invalida tal movimento por haver encontrado fora algo que ele não referenda. Nisto reside o negativo. Isto é facilmente visualizado quando autores, ao descrever situações que permitem identificar que seus personagens, proferindo discursos elogiosos e galanteadores, na verdade (ou interiormente) declamam um discurso de repreensão, amargura e crítica.

Uma vez que tal movimento, presente no romantismo, fornece as bases para o sujeito moderno (no que tange a este tornar-se objeto de reflexão e a transcender, colocando-se além do contexto determinado),

\footnotetext{
${ }^{4}$ Diferentemente de Schlegel, Hegel adota uma postura mais assertiva quanto ao que Fichte entendia por ironia. HEGEL, G. W. F. Cursos de estética - Volume I. São Paulo: Editora da Universidade de São Paulo, 2001, p. 82.

${ }^{5}$ A condição do Eu irônico de Hegel contém características do conceito de gênio trabalhado por Kant na Crítica da Faculdade do Juízo. HEGEL, G. W. F. Cursos de estética - Volume I. São Paulo: Editora da Universidade de São Paulo, 2001, p. 82.

${ }^{6}$ SAFATLE, V. "Muito longe, muito perto: dialética, ironia e cinismo a partir da leitura hegeliana de $O$ sobrinho de Rameau". Artefilosofia, Ouro Preto, n. 2, p. 36-55, jan. 2007.
}

\begin{tabular}{|c|c|l|l|l|l|}
\hline intuitio & $\begin{array}{c}\text { ISSN } \\
1983-4012\end{array}$ & Porto Alegre & Vol.9- $\mathrm{N}^{\circ} .1$ & $\begin{array}{l}\text { Julho } \\
2016\end{array}$ & p.98-110 \\
\hline
\end{tabular}


Ironia como destruição da objetividade em Macbeth: a tragédia shakespeareana à luz da teoria estética de Hegel

o sujeito irônico nunca está no lugar onde ele realmente aponta ${ }^{7}$, confirmando a ironia como um desnível entre o sentido literal do discurso e o sentido real (entendido aqui como subjetivo).

A consonância da ironia e subjetividade é indicada por Hegel, para o qual o irônico (das Ironische) consiste na autoaniquilação do esplêndido, grandioso e primoroso, num ato de subjetividade absoluta na medida em que mostra como nulo o que para os homens tem valor e dignidade (como o direito, a eticidade, o verdadeiro). O irônico difere do cômico, pois este aniquila apenas o que é nulo em si mesmo (uma mania, um capricho, uma teimosia, comumente salientados nas obras de arte como defeitos físicos ou de caráter). O irônico, por sua vez, aniquila algo que possui conteúdo e verdade ${ }^{8}$.

Diante do exposto, a ironia pode ser agora compreendida como um efeito do movimento que o indivíduo remete para o seu exterior. Ao encontrar algo na exterioridade que é diverso da sua expectativa, o indivíduo passa a conceber a realidade (aquilo que está fora dele) como algo incompleto e vazio. A partir dessa constatação, o indivíduo passa a operar em três frentes, por vezes simultâneas e excludentes entre si: numa delas, ele retorna a si e tenta preencher as lacunas da efetividade com conteúdos subjetivos, oriundos de si. Na segunda ação, ele passa a rechaçar tudo o que está presente na realidade indistintamente, voltando-se completamente para si. Na terceira, o indivíduo potencializa as instâncias lacunares do mundo, tornando-o mais degradado, a fim de fazer com que a realidade posta se torne melhor que a projetada, concebida. Nas três situações, há uso da imaginação. Uma vez que a realidade não será, nos três momentos, aceita tal qual é, o indivíduo tentará moldá-la conforme seu arbítrio. Esta modelagem se torna plástica mediante o discurso, que sempre aponta um desnível entre a realidade interior e a efetiva.

\section{A ironia como ferramenta de destruição do mundo pelo Eu segundo Hegel e Bloom}

Para Hegel, a ironia romântica é uma expressão de subjetivismo descontrolado com clara inspiração no idealismo fichteano, mas o conceito de ironia trabalhado por Schlegel se encontra na obra de Hegel. Para Hegel, a arte é o modo de o espírito expressar-se no mundo, mas que ainda não atingiu a autoconsciência, que se dará apenas após as etapas da religião e da filosofia. Assim, o espírito precisa de um anteparo material (determinado) para expressar uma ideia (indeterminado).

Nos parágrafos 207 a 230 da Fenomenologia do Espírito (FE), a certeza sensível passa para o terreno da verdade, onde ela se torna certeza-de-si, que era até então algo subjetivo, e toma a si mesma como Outro (objetivo). O Outro é para o Eu ele próprio. Mas a experiência do Eu sendo objeto de si

\footnotetext{
${ }^{7} \mathrm{O}$ Eu irônico resguarda uma negatividade que não abre espaço para a síntese. Os trabalhos de Adorno são pródigos ao abordar o caráter inconclusivo na arte após o desencanto originado após a Segunda Guerra SAFATLE, V. "Muito longe, muito perto: dialética, ironia e cinismo a partir da leitura hegeliana de $O$ sobrinho de Rameau". Artefilosofia, Ouro Preto, n. 2, p. 36-55, jan. 2007.

${ }^{8}$ HEGEL, G. W. F. Cursos de estética - Volume I. São Paulo: Editora da Universidade de São Paulo, 2001, p. 84.
}

\begin{tabular}{|c|c|l|l|l|l|}
\hline intuitio & ISSN & Porto Alegre & Vol.9- $\mathrm{N}^{\circ} .1$ & $\begin{array}{l}\text { Julho } \\
2016\end{array}$ & p.98-110 \\
\hline
\end{tabular}


Ironia como destruição da objetividade em Macbeth: a tragédia shakespeareana à luz da teoria estética de Hegel

mesmo promove uma inversão do movimento de experiência. Essa inversão é o que Hegel entende por infinitude. Mas o infinito, carregando em si sua própria eliminação, sua negação, não se aniquila, mas conserva a si na determinidade. Após tal informação, Hegel conceitua que a consciência-de-si se dá quando a infinitude se transforma em objeto para a consciência.

O Eu nunca é uma pura individualidade, mas os indivíduos são eles mesmos de natureza espiritual e contém neles estes dois momentos: o extremo da singularidade que conhece e quer para si e o extremo da universalidade que conhece e quer o que é substancial. Schlegel entendia que a ironia é a estrutura do amor, esclarecida na seguinte proporção: a arte está para o todo assim como o Dasein (ser individual) está para o ser em geral.

Ora, o Eu irônico (das Ironische), do qual Hegel fala, guarda muitas semelhanças com a consciência infeliz descrita na Fenomenologia do Espírito. A consciência-de-si é "cindida dentro de si", "duplicada", entre o imutável e o multivariado, inessencial, pois pensa ter chegado à calma da unidade. Logo, ela está enganada, pendendo para o lado mutável, que é o determinado e real. O mutável para o qual ela se inclina é a vida, o ser-aí (Dasein). A alma se percebe pura e infinita, mas apenas conceitual, em ideia. Quando ela constatar que é apenas uma abstração, ela se perceberá como algo dividido, advindo daí a sua dor. É o que Hegel chama de "nostalgia infinita".

Convém lembrar aqui que Hegel, no $§ 169$ da $F E$, entende ser a vida esta "infinita unidade das diferenças", pois a vida é um ciclo de nascimento sem fim. Deste modo, estabelece-se a consciência infeliz, que é apenas “desejo" de um ser-aí não efetivado (de um ser vivo que não se encontra no mundo). Como o que a consciência quer não é exatamente real, ela trabalha para que seu desejo se torne objeto. $\mathrm{O}$ que não ocorre, pois a consciência infeliz nunca se tornará objeto, pois seu suprassumir (atualizar-se ou, nas palavras de Hegel, submeter-se à Aufhebung) é apenas seu próprio agir, um agir sem atingir sua finalidade ${ }^{10}$.

Para o crítico estadunidense Harold Bloom, professor de Humanidades na Yale University, a primazia do $\mathrm{Eu}$ artístico na produção literária, a que ele se refere como "gênio", guarda muitas das características hegelianas do Eu artístico como o ímpeto da destruição pela ironia. Ele inclusive aduz ser a ironia, no seu antigo sentido de alegoria, o "tropo entre tropos" de ordem epistemológica, condição da própria linguagem literária, a qual produz a "permanente parábase do significado" tão cara aos desconstrucionistas ${ }^{11}$. Bloom se vale da resposta freudiana para explicar que o eu é um investimento em si

\footnotetext{
${ }^{9}$ HEGEL, G. W. F. Fenomenologia do Espírito. Petrópolis: Vozes, 2011, §§ 207-217.

${ }^{10}$ HEGEL, G. W. F. Fenomenologia do Espírito. Petrópolis: Vozes, 2011, §§ 218-221.

${ }^{11}$ BLOOM, H. The anxiety of influence. New York: Oxford University Press, 1977, p. XX. O termo "parábase" se refere aos comentários pessoais estranhos e inúteis ao enredo que o autor punha na boca do corifeu nas comédias gregas.
}

\begin{tabular}{|c|c|c|c|c|c|}
\hline intuitio & $\begin{array}{c}\text { ISSN } \\
1983-4012\end{array}$ & Porto Alegre & Vol.9- No.1 & $\begin{array}{c}\text { Julho } \\
2016\end{array}$ & p.98-110 \\
\hline
\end{tabular}


Ironia como destruição da objetividade em Macbeth: a tragédia shakespeareana à luz da teoria estética de Hegel

mesmo, que quer entender-se dentro da Natureza, que é o não-Eu. Para isto, esse Eu se mune de uma voz, que na Antiguidade era identificada como um deus que fala dentro do indivíduo ${ }^{12}$.

Bloom concebeu, na década de 1970, a teoria da "angústia da influência", na qual o leitor se vale da obra de um escritor anterior e tenta suplantá-la como escritor (aqui no papel denominado como “efebo"), num esforço de colocar seu estilo no arquivo de produção literária de seu idioma. Mesclando a doutrina cabalística e princípios freudianos, Bloom propõe que a produção literária presente está dirigindo-se ao passado e mudando-o, ou melhor, aniquilando-o, embora contenha o peso da influência pretérita $^{13}$.

A preocupação de Bloom não é entender a Literatura a partir da leitura, mas a partir de sua produção. O jovem poeta se rebela contra o mundo, contra as forças que o precederam, contra a natureza, direcionando-se a um objeto impossível, mas que ele, mediante todas as suas forças, tenta realizar. Tal ação é dada em etapas, a saber: a) o clinamen, ou o desagrilhoamento, termo relativo ao movimento dos átomos estudado por Lucrécio, entendido por Bloom como a "desleitura", o desvio do leitor ao que lê de modo a corrigir o movimento desse leitor, que passará à função de poeta; b) a Tessera, a conclusão pela antítese, termo oriundo de práticas cultuais da antiguidade, é a tentativa de complementação ao poeta lido, conferindo-lhe o que ele não pensou; c) a kenosis, ou a repetição e descontinuidade, o esvaziamento do poeta tardio, ou sua interrupção, evitando repetir os passos de seu predecessor; d) demonização, termo da literatura neoplatônica, um desvio para o antissublime, para o desmedido, em reação ao sublime, no qual o poeta efebo se individualiza "desindividualizando" o seu predecessor, ou poeta-pai, tornando sua produção algo generalizado; e) Askesis, ou a ascese, associada à purgação e ao solipsismo, momento de autoflagelação em que o poeta efebo toma o lugar do poeta anterior, tornando-se solitário em sua imaginação; f) Apophrades, ou o retorno dos mortos, quando o poeta anteriormente suplantado reaparece virtual ou estilisticamente na produção do poeta efebo ${ }^{14}$.

Ocorre que Bloom também é o representante mais conhecido da "bardolatria" na contemporaneidade. Bloom argumenta que Shakespeare criou a noção de sujeito no Ocidente, uma vez que seus personagens, longe de ser lineares, apresentam comportamentos paradoxais, o que lhes conferiria humanidade e subjetividade mais próximas do homem do que os personagens literários anteriores ou contemporâneos ao teatrólogo inglês. Esse culto muitas vezes exagerado pela importância de Shakespeare na literatura e na cultura pode ser vislumbrado, todavia, como um recurso irônico, um desafio ou proposta, na qual Shakespeare aparece hiperbolizado como uma etapa a ser cumprida pelo homem no modo, pelo menos, como o homem retrata a si mesmo na manifestação artístico-literária. É como se Shakespeare,

\footnotetext{
${ }^{12}$ BLOOM, H. Gênio: os 100 autores mais criativos da história da literatura. Rio de Janeiro: Objetiva, 2003, p. 36.

${ }^{13}$ BLOOM, H. The anxiety of influence. New York: Oxford University Press, 1997, p. XXII-XXIII.

${ }^{14}$ BLOOM, H. The anxiety of influence. New York: Oxford University Press, 1997, p. 14-16
}

\begin{tabular}{|c|c|l|l|l|l|}
\hline intuitio & $\begin{array}{c}\text { ISSN } \\
1983-4012\end{array}$ & Porto Alegre & Vol.9- $\mathrm{N}^{\mathrm{o}} .1$ & $\begin{array}{l}\text { Julho } \\
2016\end{array}$ & p.98-110 \\
\hline
\end{tabular}


Ironia como destruição da objetividade em Macbeth: a tragédia shakespeareana à luz da teoria estética de Hegel

dentro do esquema proposto por Bloom, fosse o poeta predecessor que o homem atual deve ultrapassar, desindividualizar para, assim, imprimir sua própria compreensão de si na apophrades.

Na poesia romântica (e no caso da alemã, que adotou Shakespeare como um ancestral direto de seus princípios) há a denotação apontando para um significado profundo e infinito. A despeito de a totalidade (das Ganze) não caber numa ideia como simples realidade, é necessário adotar essa transposição mediante uma postura algo mística e esotérica. Escrevendo sobre o mundo, o poeta dá sentido a algo (uma existência morosa) que restaria inerte sem a intervenção poética. As palavras do poeta produzem sentido ao mesmo tempo em que indicam um sentido localizado além delas, um sentido que tenta a consciência sempre para diante e para fora, e que nunca a satisfaz. O todo (indeterminado) é uma tentativa de significado proposto pela arte (determinada). Mas a arte, ao invés de enquadrar o todo, convida a consciência a apreender o sentido desse todo para além do limite da realidade enquadrada, rumo ao infinito. A ironia aqui é a moldura que demarca onde o determinado termina e o indeterminado começa.

\section{A ironia em Macbeth}

De modo a propor semelhanças com o recurso irônico anteriormente tratado, pode-se compreender que o Eu do artista, ao ver-se vazio e incompleto, volta-se ao mundo para suprir suas carências. Porém, vendo-o irregular e incompleto para suprir suas faltas, este Eu tenta internamente modificar esse mundo de modo a aproximá-lo a si para que, enfim, haja um encaixe entre as lacunas e saliências desse mundo com o Eu, ainda que tal ajuste seja apenas virtual, fruto da imaginação do Eu. A busca pela solução das tensões internas ao Eu pode ser assemelhada à força de repouso que caracteriza a concepção freudiana da pulsão de morte.

No contraste, Macbeth apresenta coragem externamente, mas se encontra em perpétuo estado de pavor. Em parte, pavor de tornar-se impotente, um medo relacionado tanto à imensa capacidade da imaginação do protagonista quanto ao sonho de grandeza por ele compartilhado com Lady Macbeth ${ }^{15}$.

Convém lembrar que Macbeth necessita do presságio das bruxas para dinamizar seus atos e criar sua vontade de ser rei. Lady Macbeth, ao contrário, é pura vontade, e clama às forças da noite para que lhe preencham, algo de que ela não precisa. Macbeth é dependente de Lady Macbeth, a quem lhe parece ser mãe.

Lady Macbeth, vista sob essa luz, não hesita em sacrificar a sua feminilidade em troca da coragem de cometer um homicídio pela coroa. Mantém-se impassível nos momentos posteriores ao assassínio, mesmo quando Macbeth quase se confessa assassino a outros. Ela desaparece e no último ato reaparece, já rainha, mesmerizada e sonâmbula pelo ato de haver ajudado a matar um homem. Tão empedernida de

${ }^{15}$ BLOOM, H. Shakespeare: a invenção do humano. Rio de Janeiro: Objetiva, 2001, p. 648.

\begin{tabular}{|c|c|l|l|l|l|}
\hline intuitio & $\begin{array}{c}\text { ISSN } \\
1983-4012\end{array}$ & Porto Alegre & Vol.9- $\mathrm{N}^{\circ} .1$ & $\begin{array}{l}\text { Julho } \\
2016\end{array}$ & p.98-110 \\
\hline
\end{tabular}


Ironia como destruição da objetividade em Macbeth: a tragédia shakespeareana à luz da teoria estética de Hegel

tensões interiores, a esposa de Macbeth é retirada no terceiro ato, para apenas voltar como louca no quinto, seguindo uma decisão que Shakespeare tomava de modo a evitar que os personagens secundários "roubassem" a cena, assim como fez matando Mercúcio em Romeu e Julieta e Falstaff no Henrique V. O desejo que os Macbeth sentem um pelo outro é também o desejo pelo trono, como uma vingança contra o tempo e seu atributo de obsolescer as coisas, uma vez que eles não possuíam filhos ${ }^{16}$.

Notar-se-á que em Macbeth, Shakespeare lança mão dos três recursos de discurso irônico. No primeiro caso, os assassinatos que o protagonista comete para legitimar a sua interpretação do augúrio das bruxas são tentativas de aplainar a efetividade com o projeto individual do personagem. Num segundo nível, Macbeth elimina qualquer conteúdo moral (como valor socialmente sedimentado) de suas ações para impor à realidade os seus próprios valores. Na terceira frente, Shakespeare tinge a Escócia com tintas expressionistas e escuras, deteriorando uma instância espaço-temporal diferente da existente no medievo.

Não se deve esquecer que Shakespeare poderá ter usado sua ironia com imaginação. Para Jennifer Bates, a imaginação, entendida por Hegel, é necessária para completar a liberdade, embora não seja suficiente, uma vez que a imaginação se ampara na formação educacional (Bildung), a qual se limita pelo modo como as instituições estatais a ofertam no seu tempo ${ }^{17}$. Segundo a autora, toda a imaginação é moral. Assim, a imaginação é resultante da formação educacional, sendo a liberdade (e com ela o reconhecimento do que está fora) limitada pelas instituições.

Há uma aproximação com o que Hegel entendia por ironia e o que Freud tomava por pulsão. No sentido de estabelecer a pulsão de morte, Freud aponta que, para a constituição do aparelho psíquico, deve-se pressupor, ao invés de um prazer, um desprazer mais originário, sendo a pulsão de morte o limite a essa genealogia freudiana do desprazer ${ }^{18}$. Nesse sentido, as bases do Eu que se volta para o mundo é o seu vazio. Quando o ser constata o negativo, o ausente em si, ele se dirige ao mundo para complementarse. O negativo hegeliano, que compele o Eu ao mundo, pode ser relacionado à pulsão de desprazer originária, a pulsão de morte.

A ironia amalgamada ao Eu hegeliano que tenta adequar o mundo exterior ao interior do indivíduo conserva características com a pulsão de morte elaborada por Freud. Caracterizada como uma propensão do orgânico, que é dinâmico, a voltar para o inorgânico, que é o repouso, algo similar à pulsão de morte já havia sido vislumbrado por Hegel, também nos Cursos de Estética (2002). Para Hegel, a natureza tende ao repouso. Como a vida é um arranjo que, para ser mantido, exige energias oriundas da natureza,

${ }^{16}$ BLOOM, Harold. Shakespeare: a invenção do humano. Rio de Janeiro: Objetiva, 2001, p. 633-638; FREUD, Sigmund. "Arruinados pelo êxito". In: Edição Standard Brasileira das obras psicológicas completas de Sigmund Freud - Volume XIV. Rio de Janeiro: Imago Editora, 1986, p. 359-361.

${ }^{17}$ BATES, Jennifer Ann. Hegel and Shakespeare on Moral Imagination. New York: State University of New York Press, 2010.

${ }_{18}$ MONTENEGRO, Maria Aparecida de Paiva. Pulsão de morte e racionalidade no pensamento freudiano. Fortaleza: Editora UFC, 2002, p. 32.

\begin{tabular}{|c|c|c|c|c|c|}
\hline intuitio & $\begin{array}{c}\text { ISSN } \\
1983-4012\end{array}$ & Porto Alegre & Vol.9- $\mathrm{N}^{\circ} .1$ & $\begin{array}{l}\text { Julho } \\
2016\end{array}$ & p.98-110 \\
\hline
\end{tabular}


Ironia como destruição da objetividade em Macbeth: a tragédia shakespeareana à luz da teoria estética de Hegel

provocando tensões e desgastes, a própria Natureza empreende tentativas para eliminar tais tensões. O repouso da forma de vida se encontra na sua finalização, sua morte.

É mister destacar que Freud também já se debruçou sobre a peça Macbeth e, na tentativa de compreender, muito mais que o personagem principal, a dinâmica interna de Lady Macbeth, afirma por conclusão ao apresentado no texto shakespeareano a existência da tese de que as pessoas adoecem de neurose como resultado de frustração. A neurose é ocasionada pelo conflito entre os desejos libidinais e o ego (expressão do instinto de autopreservação e que abrange os ideais da personalidade). O conflito se dá quando a libido tenta alcançar objetivos que o ego já superou e condenou, tornando-se privada de sua satisfação $^{19}$. De forma surpreendente, ocorre o adoecimento de pessoas no momento preciso em que um desejo profundamente enraizado atinge sua realização, pondo a termo a fruição do mesmo.

Pode-se distinguir a frustração interna da externa. A frustração externa se dá quando o objeto no qual a libido se direciona está contido na realidade. A frustração interna provém do ego, quando este disputa o acesso da libido a outros objetos aos quais ela procura apreender. A frustração interna é posterior à frustração externa. No caso da frustração pelo êxito, o ego empreende esforços para conter o desejo de algo ansiado que esteja próximo.

Segundo Bloom, a intenção de Shakespeare na "peça escocesa" (termo usado pelos antigos para não citar o nome Macbeth, por acreditarem que o texto contivesse uma espécie de maldição) é levar o espectador a empreender uma jornada ao mais nefasto interior do personagem, onde o homem encontra a si mesmo, naquilo que ele tem de mais autêntico e estranho (umheimlich, não familiar no alemão, adjetivo empregado por Freud em seu trabalho), como assassino em espírito e do espírito, num calabouço que serve tanto aos tiranos quanto às vítimas. Macbeth, o usurpador, move-se em meio a uma fantamasgoria de sangue, dado que o sangue é o componente básico de sua imaginação. É de Bloom a assertiva de que a indubitável ironia em Macbeth não resulta de perspectivas conflitantes, mas de divisões dentro do próprio $\mathrm{Eu}$ interior, tanto de Macbeth quanto do público. Bloom visualiza o personagem Macbeth como pessoa dotada de inteligência abaixo da média, mas com tamanha capacidade de fantasiar a ponto de torná-lo uma máquina mortífera. Essa capacidade inventiva de Macbeth é amparada pelo ambiente da peça cercado de fantasmagoria, presente nos mortos que aparecem ao seu assassino e, em maior grau, às bruxas predicantes. Porém, a bruxaria, bem entendido, não é capaz de alterar os fatos, mas a alucinação é capaz de fazê-lo, o que realmente faz ${ }^{20}$.

Na busca pelo lúgubre e desconhecido, procura-se o limite moral da imaginação (entendida na Renascença como fantasia) com a apresentação de figuras fantasmais. Bloom enxerga em Macbeth tal

\footnotetext{
${ }^{19}$ FREUD, Sigmund. “Arruinados pelo êxito". In: Edição Standard Brasileira das obras psicológicas completas de Sigmund Freud - Volume XIV. Rio de Janeiro: Imago Editora, 1986, p. 357.

${ }^{20}$ BLOOM, H. Shakespeare: a invenção do humano. Rio de Janeiro: Objetiva, 2001, p 632-653.
}

\begin{tabular}{|c|c|l|l|l|l|}
\hline intuitio & $\begin{array}{c}\text { ISSN } \\
1983-4012\end{array}$ & Porto Alegre & Vol.9- $\mathrm{N}^{\circ} .1$ & $\begin{array}{l}\text { Julho } \\
2016\end{array}$ & p.98-110 \\
\hline
\end{tabular}


Ironia como destruição da objetividade em Macbeth: a tragédia shakespeareana à luz da teoria estética de Hegel

capacidade imaginativa, aqui potencializada por um caráter profético, algo que, segundo ele, seria comum a todas as pessoas. Em Macbeth, porém, esse tipo de imaginação tem um valor absoluto, visto que o personagem, logo que se percebe com uma ambição, já é capaz de ver a si mesmo cometendo o crime que, equivocamente, satisfaz a referida ambição. Tal atitude evoca a segunda frente na qual o Eu impõe à realidade a forma subjetiva. Não é de forma gratuita que Macbeth "aterroriza-nos, em parte, porque nossa imaginação tem um lado assustador, fazendo-nos parecer assassinos, ladrões, usurpadores e estupradores" 21 .

Com efeito, as bruxas são seres reais, embora nada acresçam à trama. Macbeth possui mais poder que elas, pois ele age, enquanto elas apenas prenunciaram atos que seriam de forma ou outra perpetrados por ele. Isso seria um traço irônico citado por Bloom, mas que pode ser refutado, pois Macbeth poderia ter a consciência de sua capacidade adormecida, cabendo às bruxas despertar esse papel. Outro descompasso da tragédia digno de nota é identificado por Bloom como grande ironia, quando Shakespeare apresenta o casal Macbeth como o mais feliz de toda a sua obra dramática, não sendo demoníacos, ainda que hajam perpetrado terríveis crimes ${ }^{22}$.

A terceira dinâmica do Eu em um mundo com o qual não se identifica é piorá-lo, degradá-lo e despi-lo de toda e qualquer amenidade. Bloom percebe que o cosmo de Macbeth é mais drástico e alienado até mesmo do que o de Rei Lear, em que a Natureza é ferida tão profundamente. Dado que em Rei Lear a realidade é pré-cristã, em Macbeth ela é nitidamente medieval e católica, parecendo menos localizada na Escócia do que no kenoma, o vazio cosmológico do mundo, segundo a descrição dos antigos hereges gnósticos. Nas palavras de Bloom, "Macbeth é uma espécie de noturno; a Escócia da peça é mais uma região mitológica setentrional do que a terra do monarca que é o patrono de Shakespeare”. Nela, a noite usurpa o dia. O cosmo de Macbeth, como o de Moby Dick (outra grande obra escrita em língua inglesa, para Bloom), desconhece o Salvador; "a charneca e o mar são imensas mortalhas, de onde os mortos não ressuscitarão". Convém lembrar que o elemento notoriamente dominante na peça é o tempo, não o tempo no sentido misericordioso cristão, como eternidade, mas o tempo voraz, a morte encarada, niilisticamente, como o fim ${ }^{23}$.

A identificação do espectador/leitor com Macbeth é total porque ele reconhece a noção de desrespeito à natureza humana. Em Macbeth não há catarse ou purgação do que a humanidade poderia malignamente executar. O que ocorre é o inverso: Shakespeare faz com que o espectador se perceba potencialmente assassino ao implantar no seu interior a figura de um homem comum que desperta para o agir homicida e que se vê conscientemente incapaz de deter a si mesmo ${ }^{24}$.

\footnotetext{
${ }^{21}$ BLOOM, H. Shakespeare: a invenção do humano. Rio de Janeiro: Objetiva, 2001, p. 633.

${ }^{22}$ BLOOM, H. op. cit., p. 634, 650.

${ }^{23}$ BLOOM, H. op. cit., p. 634-642.

${ }^{24}$ BLOOM, H. op. cit., p. 644, 653.
}

\begin{tabular}{|c|c|c|c|c|c|}
\hline intuitio & $\begin{array}{c}\text { ISSN } \\
1983-4012\end{array}$ & Porto Alegre & Vol.9- $\mathrm{N}^{\circ} .1$ & $\begin{array}{l}\text { Julho } \\
2016\end{array}$ & p.98-110 \\
\hline
\end{tabular}




\section{Considerações finais}

A leitura da peça de Shakespeare Macbeth é exemplo de uma obra literária que pode ser objeto de demonstração filosófica. O conceito de ironia mostra-se, nesse sentido, como ferramenta sobejamente utilizada pelo autor/artista de modo a salientar aspectos degenerados do mundo, dando ao caráter prosaico da realidade um matiz estético. $\mathrm{O}$ ato de plasmar características da realidade para comunicar impressões e estados espirituais é uma tarefa do artista que não pode ser submetida, no dizer de Hegel, a julgamento ou censura, pois este é o modo particular de aparecer segundo o qual a arte dá efetividade ao que é verdadeiro em si mesmo, ou o substancial da natureza do espírito. É também do próprio Hegel o fundamento da ironia, identificado em Macbeth, no aspecto em que as bruxas são elementos externos que proclamam o mais oculto desejo do personagem-título, tornando esse elemento enterrado em seu coração como algo revelado a ele por meio da aparição (Erscheinung) ${ }^{25}$. Desse modo, o irônico é o mundo interior do sujeito tornado efetividade pela arte. As ciências do espírito se tornam, assim, ferramentas que podem enriquecer a obra de significado, da mesma feita como a obra em pauta pôde ter vislumbrados os matizes sobre a alteração da realidade pelo recurso irônico.

Com efeito, o grotesco convite de Shakespeare para o espectador/leitor é mostrá-lo que não faz o papel de vítima de Macbeth, mas recebe a possibilidade de encontrar Macbeth em si mesmo, no momento em que ele pode assassinar mentalmente. Isso remete ao conceito de "estranho" freudiano. O estranho é categoria do assustador que remete ao que é conhecido, de velho e há muito familiar. Esse estranho (umheimlich) é o nome de tudo que deveria ter permanecido secreto e oculto, mas veio à luz. A palavra tem raiz no alemão heimlich, aquilo que é familiar, do lar, privado, que permanece em segredo. Assim, o Eu de Macbeth, que odeia, abomina e persegue, com a intenção de destruir todos os objetos que lhe são desagradáveis, pode ser encontrado no interior de qualquer ser humano. A origem do ódio, para Freud, não se deve à sexualidade, mas à luta do Eu para preservar-se e manter-se, e que em Macbeth é o que está oculto e íntimo no ser humano.

\section{Referências}

BATES, Jennifer Ann. Hegel and Shakespeare on Moral Imagination. New York: State University of New York Press, 2010, 402 pgs.

BLOOM, Harold. The anxiety of influence. New York: Oxford University Press, 1997.

. Gênio: os 100 autores mais criativos da história da literatura. Rio de Janeiro: Objetiva, 2003.

Shakespeare: a invenção do humano. Rio de Janeiro: Objetiva, 2001.

\footnotetext{
${ }^{25}$ HEGEL, G. W. F. Cursos de Estética - vol. I. São Paulo: Edusp, 2001, p. 33, 237.
}

\begin{tabular}{|c|c|l|l|l|l|}
\hline intuitio & $\begin{array}{c}\text { ISSN } \\
1983-4012\end{array}$ & Porto Alegre & Vol.9- $\mathrm{N}^{\circ} .1$ & $\begin{array}{l}\text { Julho } \\
2016\end{array}$ & p.98-110 \\
\hline
\end{tabular}


Ironia como destruição da objetividade em Macbeth: a tragédia shakespeareana à luz da teoria estética de Hegel

EGGINTON, William. "Cervantes, Irony and making of reality". $M L N$, Volume 117, Number 5, December 2002 (Comparative Literature Issue), pp. 1040-1068 (Article) Johns Hopkins University Press.

FREUD, Sigmund. "Arruinados pelo êxito". In: Edição Standard Brasileira das obras psicológicas completas de Sigmund Freud - Volume XIV. Rio de Janeiro: Imago Editora, 1986.

HEGEL, G. W. F. Cursos de estética - Volume I. São Paulo: Editora da Universidade de São Paulo, 2001. . On Tragedy. Westport (USA): Greenwood Press, 1962.

MONTENEGRO, Maria Aparecida de Paiva. Pulsão de morte e racionalidade no pensamento freudiano. Fortaleza: Editora UFC, 2002.

SAFATLE, Vladimir. Muito longe, muito perto: dialética, ironia e cinismo a partir da leitura hegeliana de $O$ sobrinho de Rameau. Artefilosofia, Ouro Preto, n. 2, p. 36-55, jan. 2007.

SHAKESPEARE, William. Macbeth. São Paulo: Agir, 2008. . Macbeth. Rio de Janeiro: Nova Aguilar, 1998. . Macbeth. Hertfordshire (Great Britain): Wordsworth Editions, 1996.

Recebido em: 26/04/2015

Aprovado para a publicação em: 09/12/2015

\begin{tabular}{|l|c|l|l|l|l|}
\hline intuitio & $\begin{array}{c}\text { ISSN } \\
1983-4012\end{array}$ & Porto Alegre & Vol.9- $\mathrm{N}^{\mathrm{o}} .1$ & $\begin{array}{l}\text { Julho } \\
2016\end{array}$ & p.98-110 \\
\hline
\end{tabular}

